\title{
Modeling of the Effect of Freezer Conditions on the Principal Constituent Parameters of Ice Cream by Using Response Surface Methodology
}

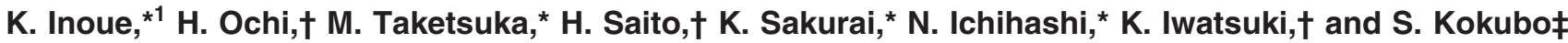 \\ ${ }^{*}$ Food Research \& Development Institute, \\ †Food Science \& Technology Institute, and \\ †Research \& Development, Morinaga Milk Industry Co., Ltd., 1-83, 5-Chome Higashihara, Zama, Kanagawa 228-8583, Japan
}

\begin{abstract}
A systematic analysis was carried out by using response surface methodology to create a quantitative model of the synergistic effects of conditions in a continuous freezer [mix flow rate $(\mathrm{L} / \mathrm{h})$, overrun $(\%)$, cylinder pressure $(\mathrm{kPa})$, drawing temperature $\left({ }^{\circ} \mathrm{C}\right)$, and dasher speed (rpm)] on the principal constituent parameters of ice cream [rate of fat destabilization (\%), mean air cell diameter $(\mu \mathrm{m})$, and mean ice crystal diameter $(\mu \mathrm{m})]$. A central composite face-centered design was used for this study. Thirty-one combinations of the 5 above-mentioned freezer conditions were designed (including replicates at the center point), and ice cream samples were manufactured and examined in a continuous freezer under the selected conditions. The responses were the 3 variables given above. A quadratic model was constructed, with the freezer conditions as the independent variables and the ice cream characteristics as the dependent variables. The coefficients of determination $\left(R^{2}\right)$ were greater than 0.9 for all 3 responses, but $Q^{2}$, the index used here for the capability of the model for predicting future observed values of the responses, was negative for both the mean ice crystal diameter and the mean air cell diameter. Therefore, pruned models were constructed by removing terms that had contributed little to the prediction in the original model and by refitting the regression model. It was demonstrated that these pruned models provided good fits to the data in terms of $R^{2}, Q^{2}$, and ANOVA. The effects of freezer conditions were expressed quantitatively in terms of the 3 responses. The drawing temperature $\left({ }^{\circ} \mathrm{C}\right)$ was found to have a greater effect on ice cream characteristics than any of the other factors.
\end{abstract}

Key words: ice cream, response surface methodology, continuous freezer

Received October 21, 2007.

Accepted February 5, 2008.

${ }^{1}$ Corresponding author: ke-inoue@morinagamilk.co.jp

\section{INTRODUCTION}

Ice cream is a complex food colloid that consists of air bubbles, fat globules, ice crystals, and an unfrozen serum phase (Goff, 1997). Various steps in the manufacturing process, including pasteurization, homogenization, aging, freezing, and hardening, contribute to the development of this structure.

Freezing is one of the most important processes in the commercial production of ice cream, because this process causes a variety of fundamental changes to occur in the ice cream mix. In this process, ice cream mix introduced into a cylindrical freezer barrel is frozen quickly, and as ice crystals are formed, air is injected into it under pressure. At the same time, considerable shear stress is applied to the mix, and the shear promotes the partial coalescence or destabilization of the fat globules that were originally emulsified by the homogenizer. The clumps and clusters of fat globules form and build an internal fat structure or network in the frozen product by entrapping air within the coalesced fat (Goff, 1997).

There have been many reports on the influence of freezing conditions on ice cream. Kokubo et al. (1996) reported that the drawing temperature and overrun control the fat destabilization. Bolliger et al. (2000) reported that fat agglomerate size is controlled by mechanical shear. Goff and Jordan (1989) reported that the combination of the shear forces and ice crystallization influence fat destabilization and that using only one or the other factor is an inefficient way to influence the magnitude of fat destabilization. Russell et al. (1999) demonstrated that ice crystallization in the freezer depends more on the recrystallization process than on nucleation, and further, that it is possible to minimize the fusion of ice crystals during recrystallization by minimizing the residence time for the ice cream mix in the freezer.

Nevertheless, although previous reports have described the effects on ice cream by manipulating the processes and conditions of single factors, no publica- 
Table 1. Coded and uncoded settings of the freezer condition, according to a central composite face-centered design

\begin{tabular}{lcccccc}
\hline & \multicolumn{2}{c}{ Symbol } & & \multicolumn{3}{c}{ Level } \\
\cline { 2 - 3 } \cline { 5 - 7 } Freezer condition & Coded & Uncoded & & -1 & 0 & +1 \\
\hline Mix flow $(\mathrm{L} / \mathrm{h})$ & $\mathrm{X} 1$ & Mix & & 50 & 75 & 100 \\
Drawing temperature $\left({ }^{\circ} \mathrm{C}\right)$ & $\mathrm{X} 2$ & Tem & & -6.5 & -5.0 & -3.5 \\
Overrun $(\%)$ & $\mathrm{X} 3$ & Ovr & & 30 & 75 & 120 \\
Cylinder pressure $(\mathrm{kPa})$ & $\mathrm{X} 4$ & Cyl & & 150 & 300 & 450 \\
Dasher speed $(\mathrm{rpm})$ & $\mathrm{X} 5$ & Das & & 114 & 222 & 330 \\
\hline
\end{tabular}

tions have ever presented detailed, quantitative studies of the synergistic effects of multiple conditions on an ice cream mix.

Response surface methodology is a very effective systematic approach for making quantitative models of the effects of simultaneous changes in multiple parameters and optimizing these parameters. It has been used in food processing (van der Ven et al., 2002; Koc et al., 2003; Ünal et al., 2003). However, we found no reports except for the following one that have investigated frozen desserts by using this methodology.

Tong et al. (1984) reported on the effects of safflower oil concentration, emulsifier concentration, and freezing temperature on the maximum overrun and fat destabilization of ice cream when using response surface methodology. A batch freezer was used in their tests, and overrun was set as one of the dependent variables. However, the continuous freezer has recently become the main tool for ice cream manufacturing. The continuous freezer has several controllable factors that give us many choices in designing different characteristics of ice cream. Overrun is one of the controllable factors for the continuous freezer and is an independent variable, unlike in previous studies.

Ordinarily, response surface methodology is used with the design of the experiment to obtain a more fittable regression equation, that is, to reduce the variance of the coefficients in the regression equation. Typically, the actual response function is approximated with a quadratic polynomial model that consists of the main terms, second-order terms, and interaction terms.

The purpose of this study was to create a response surface model that would reproduce the effects on 3 aspects of ice cream structure [rate of fat destabilization (FAT), mean air cell diameter (AIR), and mean ice crystal diameter (ICE)] caused by 5 essential freezer conditions [mix flow rate $(\mathrm{L} / \mathrm{h})$, overrun $(\%)$, cylinder pressure $(\mathrm{kPa})$, drawing temperature $\left({ }^{\circ} \mathrm{C}\right)$, and dasher speed (rpm)] when using a continuous freezer.

\section{MATERIALS AND METHODS}

\section{Preparation of Ice Cream Samples}

Test ice cream mix formulations was based on $11.32 \%$ unsalted butter (Morinaga Milk Industry Co., Ltd.,
Tokyo, Japan), $10.13 \%$ skim milk powder (Morinaga Milk Industry Co., Ltd.), $7.5 \%$ sucrose (Dai-Nippon Meiji Sugar Co., Ltd., Tokyo, Japan), 7.0\% corn syrup (TS 67.5\%, Sanwa Cornstarch Co., Ltd., Nara, Japan), 6.0\% dextrin (Showa Sangyo Co., Ltd., Tokyo, Japan), $0.25 \%$ emulsifier (glyceryl monodistearate, Taiyo Kagaku Co., Ltd., Mie, Japan), and $0.25 \%$ stabilizers ( $45 \%$ locust bean gum, $45 \%$ guar gum, and $10 \%$ carrageenan, Taiyo Kagaku Co., Ltd.). The mix contained 9.5\% milk fat, 9.8\% nonfat milk solids, and TS of $37.8 \%$.

Ice cream mix was prepared by adding the dry ingredients to water at $70^{\circ} \mathrm{C}$ by using a high-shear blender (Yasuda Co., Ltd., Tokyo, Japan). The mix was pasteurized for $30 \mathrm{~s}$ at $95^{\circ} \mathrm{C}$ in a plate heat exchanger (MD Plate Exchanger FBS-3 SS, Morinaga Engineering, Tokyo, Japan), and homogenized in a 2-stage homogenizer (Sanmaru, Mishima, Japan) at 15.0 and 5.0 MPa. It was then cooled to $5^{\circ} \mathrm{C}$ and aged for a full day.

According to the experimental design described below, samples were frozen in a continuous freezer (model CS-200-R404A, CP Engineering Inc., Tokyo, Japan) and added to $130-\mathrm{mL}$ conical sampling cups. The dasher was a standard type no. 30 . The samples were stored at $-35^{\circ} \mathrm{C}$.

\section{FAT}

The method of Kokubo et al. (1996) was used to measure the amount of fat destabilization. The ice cream was diluted to triple its original volume by using deionized water at 5 to $10^{\circ} \mathrm{C}$ and was gently agitated for a full day to remove the air while maintaining consistency. The sample was then diluted by factors of 100 to 2,000 , and the distribution in size of the agglomerated fat globules was observed with a laser diffraction particle-size distribution analyzer (model LA-500, Horiba, Ltd., Kyoto, Japan).

The particle size diameter index for the accumulation of all particles in the particle size distribution of ice cream mix was $90 \%$ (vol/vol). Next, the accumulation of particles of lower diameter, $\mathrm{X} \%$ (vol/vol), was subtracted from the particle size distribution during freezing and was used as an indicator. This difference in accumula- 
Table 2. Central composite face-centered design ${ }^{1}$

\begin{tabular}{|c|c|c|c|c|c|c|c|c|c|c|}
\hline \multirow[b]{2}{*}{ Experiment no. } & \multicolumn{5}{|c|}{ Factor } & \multicolumn{5}{|c|}{ Coded factor } \\
\hline & Mix & Tem & Ovr & Cyl & Das & Mix & Tem & Ovr & $\mathrm{Cyl}$ & Das \\
\hline 1 & 50 & -6.5 & 120 & 150 & 114 & -1 & -1 & 1 & -1 & -1 \\
\hline 2 & 50 & -3.5 & 30 & 150 & 114 & -1 & 1 & -1 & -1 & -1 \\
\hline 3 & 100 & -6.5 & 30 & 150 & 114 & 1 & -1 & -1 & -1 & -1 \\
\hline 4 & 100 & -3.5 & 120 & 150 & 114 & 1 & 1 & 1 & -1 & -1 \\
\hline 5 & 50 & -6.5 & 30 & 450 & 114 & -1 & -1 & -1 & 1 & -1 \\
\hline 6 & 50 & -3.5 & 120 & 450 & 114 & -1 & 1 & 1 & 1 & -1 \\
\hline 7 & 100 & -6.5 & 120 & 450 & 114 & 1 & -1 & 1 & 1 & -1 \\
\hline 8 & 100 & -3.5 & 30 & 450 & 114 & 1 & 1 & -1 & 1 & -1 \\
\hline 9 & 50 & -6.5 & 30 & 150 & 330 & -1 & -1 & -1 & -1 & 1 \\
\hline 10 & 50 & -3.5 & 120 & 150 & 330 & -1 & 1 & 1 & -1 & 1 \\
\hline 11 & 100 & -6.5 & 120 & 150 & 330 & 1 & -1 & 1 & -1 & 1 \\
\hline 12 & 100 & -3.5 & 30 & 150 & 330 & 1 & 1 & -1 & -1 & 1 \\
\hline 13 & 50 & -6.5 & 120 & 450 & 330 & -1 & -1 & 1 & 1 & 1 \\
\hline 14 & 50 & -3.5 & 30 & 450 & 330 & -1 & 1 & -1 & 1 & 1 \\
\hline 15 & 100 & -6.5 & 30 & 450 & 330 & 1 & -1 & -1 & 1 & 1 \\
\hline 16 & 100 & -3.5 & 120 & 450 & 330 & 1 & 1 & 1 & 1 & 1 \\
\hline 17 & 75 & -6.5 & 75 & 300 & 222 & 0 & -1 & 0 & 0 & 0 \\
\hline 18 & 75 & -3.5 & 75 & 300 & 222 & 0 & 1 & 0 & 0 & 0 \\
\hline 19 & 50 & -5.0 & 75 & 300 & 222 & -1 & 0 & 0 & 0 & 0 \\
\hline 20 & 100 & -5.0 & 75 & 300 & 222 & 1 & 0 & 0 & 0 & 0 \\
\hline 21 & 75 & -5.0 & 75 & 150 & 222 & 0 & 0 & 0 & -1 & 0 \\
\hline 22 & 75 & -5.0 & 75 & 450 & 222 & 0 & 0 & 0 & 1 & 0 \\
\hline 23 & 75 & -5.0 & 75 & 300 & 114 & 0 & 0 & 0 & 0 & -1 \\
\hline 24 & 75 & -5.0 & 75 & 300 & 330 & 0 & 0 & 0 & 0 & 1 \\
\hline 25 & 75 & -5.0 & 30 & 300 & 222 & 0 & 0 & -1 & 0 & 0 \\
\hline 26 & 75 & -5.0 & 120 & 300 & 222 & 0 & 0 & 1 & 0 & 0 \\
\hline 27 & 75 & -5.0 & 75 & 300 & 222 & 0 & 0 & 0 & 0 & 0 \\
\hline 28 & 75 & -5.0 & 75 & 300 & 222 & 0 & 0 & 0 & 0 & 0 \\
\hline 29 & 75 & -5.0 & 75 & 300 & 222 & 0 & 0 & 0 & 0 & 0 \\
\hline 30 & 75 & -5.0 & 75 & 300 & 222 & 0 & 0 & 0 & 0 & 0 \\
\hline 31 & 75 & -5.0 & 75 & 300 & 222 & 0 & 0 & 0 & 0 & 0 \\
\hline
\end{tabular}

${ }^{1} \mathrm{Mix}=\operatorname{mix}$ flow $(\mathrm{L} / \mathrm{h}) ; \mathrm{Tem}=$ drawing temperature $\left({ }^{\circ} \mathrm{C}\right) ; \mathrm{Ovr}=$ overrun $(\%) ; \mathrm{Cyl}=$ cylinder pressure $(\mathrm{kPa}) ;$ Das $=$ dasher speed $(\mathrm{rpm})$.

tion around the time of freezing $(90 \%-\mathrm{X} \%$, vol/vol) was calculated as the FAT.

\section{AIR and ICE}

The AIR were measured by using a cryo-scanning electron microscope. The hardened ice cream was frozen and then sliced in liquid nitrogen. The slices were placed on the previously chilled grid and inserted into an SM-200 scanning electron microscope (Topcon Co., Ltd., Tokyo, Japan) to which a liquid nitrogen cold module (C1002, Gatan UK, Oxford, UK) was attached. The scanning electron microscope chamber was held at $-95^{\circ} \mathrm{C}$ to deaerate the samples by sublimation, and the samples were etched. The images of the ice cream mix were analyzed with Image Pro Plus version 4.0 software (Media Cybernetics, Bethesda, MD) and the equivalent diameters of the circles were calculated. The means of those values were stored as the AIR value.

In accordance with the method of Christensen and Andersen (2003), the ice crystals were observed directly with an optical microscope (Nikon Eclipse E400, Nikon Co., Ltd., Tokyo, Japan) equipped with a refrigerated glovebox (Donhowe et al., 1991). The glovebox temperature was set at $-15^{\circ} \mathrm{C}$. For ice crystal size analysis, a small sample of ice cream was placed on a prechilled microscope slide (equilibrated in the glovebox), dispersed with a few drops of $n$-butanol, and smeared into a thin layer with a second slide placed on the top of the sample. The images were analyzed with Image Pro Plus version 4.0 software, and the equivalent diameters of the circles were calculated and stored as the ICE value.

\section{Design of Experiments}

A central composite face-centered design was used for this course of experiments, which included the 5 freezer conditions as factors and the 3 constituent parameters as responses. Tables 1 and 2 show the uncoded and coded terminology and the settings. With consideration given to the mechanical limits of the freezer and the practical settings for actual ice cream production, the upper and lower settings at which the freezer functioned were chosen as the extreme factors.

The quadratic model shown below was used for modeling the factors and responses; it incorporated main 
Table 3. Actual freezer conditions during sampling and the 3 responses $^{1}$

\begin{tabular}{|c|c|c|c|c|c|c|c|c|}
\hline \multirow[b]{2}{*}{ Experiment no. } & \multicolumn{5}{|c|}{ Coded factor } & \multicolumn{3}{|c|}{ Response } \\
\hline & Mix & Tem & Ovr & Cyl & Das & FAT & AIR & ICE \\
\hline 1 & -1 & -1 & 1 & -1 & -1 & 82.44 & 24.91 & 45.96 \\
\hline 2 & -1 & 1 & -1 & -1 & -1 & 5.23 & 45.76 & 81.28 \\
\hline 3 & 1 & -1 & -1 & -1 & -1 & 65.79 & 23.64 & 28.90 \\
\hline 4 & 1 & 1 & 0.56 & -1 & -1 & 15.00 & 95.89 & 76.52 \\
\hline 5 & -1 & -1 & -1 & 1 & -1 & 51.16 & 24.11 & 49.27 \\
\hline 6 & -1 & 1 & 0.56 & 1 & -0.6 & 10.89 & 98.18 & 77.47 \\
\hline 7 & 1 & -1 & 0.56 & 1 & -0.6 & 80.13 & 35.89 & 30.13 \\
\hline 8 & 1 & 1 & -1 & 1 & -1 & 0.00 & 71.64 & 79.48 \\
\hline 9 & -1 & -1 & -1 & -1 & 1 & 84.92 & 27.96 & 51.78 \\
\hline 10 & -1 & 1 & 1 & -1 & 1 & 35.42 & 44.94 & 49.77 \\
\hline 11 & 1 & 0.2 & 0.78 & -1 & 1 & 88.41 & 30.33 & 39.14 \\
\hline 12 & 1 & 1 & -1 & -1 & 1 & 8.65 & 33.79 & 56.14 \\
\hline 13 & -1 & -1 & 1 & 1 & 1 & 97.25 & 25.99 & 43.92 \\
\hline 14 & -1 & 1 & -1 & 1 & 1 & 6.11 & 46.40 & 66.99 \\
\hline 15 & 1 & -1 & -1 & 1 & 1 & 64.79 & 24.31 & 47.73 \\
\hline 16 & 1 & 1 & 1 & 1 & 1 & 23.37 & 73.35 & 56.81 \\
\hline 17 & 0 & -1 & 0 & 0 & 0 & 80.69 & 28.80 & 41.90 \\
\hline 18 & 0 & 1 & 0 & 0 & 0 & 19.55 & 66.69 & 65.52 \\
\hline 19 & -1 & 0 & 0 & 0 & 0 & 56.54 & 33.18 & 56.27 \\
\hline 20 & 1 & 0 & 0 & 0 & 0 & 56.70 & 41.65 & 41.48 \\
\hline 21 & 0 & 0 & 0 & -1 & 0 & 60.14 & 40.02 & 43.04 \\
\hline 22 & 0 & 0 & 0 & 1 & 0 & 48.36 & 33.97 & 53.78 \\
\hline 23 & 0 & 0 & 0 & 0 & -1 & 40.33 & 58.10 & 45.54 \\
\hline 24 & 0 & 0 & 0 & 0 & 1 & 59.10 & 40.50 & 47.86 \\
\hline 25 & 0 & 0 & -1 & 0 & 0 & 23.69 & 28.53 & 46.04 \\
\hline 26 & 0 & 0 & 1 & 0 & 0 & 74.10 & 37.10 & 37.40 \\
\hline 27 & 0 & 0 & 0 & 0 & 0 & 64.44 & 36.86 & 51.02 \\
\hline 28 & 0 & 0 & 0 & 0 & 0 & 53.87 & 33.82 & 45.92 \\
\hline 29 & 0 & 0 & 0 & 0 & 0 & 64.28 & 25.72 & 41.36 \\
\hline 30 & 0 & 0 & 0 & 0 & 0 & 48.25 & 39.28 & 42.36 \\
\hline 31 & 0 & 0 & 0 & 0 & 0 & 51.14 & 34.93 & 48.06 \\
\hline
\end{tabular}

${ }^{1}$ Numbers $4,6,7$, and 11 could not be taken in exact accordance with the original central composite facecentered design, but were taken in conditions as close to the planned conditions as possible. Mix = mix flow; $\mathrm{Tem}=$ drawing temperature; Ovr = overrun; $\mathrm{Cyl}=$ cylinder pressure; Das = dasher speed; FAT = rate of fat destabilization $(\%)$; AIR = mean air cell diameter $(\mu \mathrm{m})$; ICE $=$ mean ice crystal diameter $(\mu \mathrm{m})$.

effects, quadratic effects, interactions, and a constant. The model parameters were predicted in a least squares multiple regression analysis.

$$
Y=b_{0}+\sum_{i=1}^{5} b_{i} X_{i}+\sum_{i=1}^{5} b_{i i} X_{i}^{2}+\sum_{i=1}^{4} \sum_{j=2}^{5} b_{i j} X_{i} X_{j}(i<j)
$$

where $Y$ is the response; $X_{i}$ and $X_{j}$ are the levels of the factors; $b_{0}$ is a constant; and $b_{i}, b_{i i}$, and $b_{i j}$ are the coefficients for the main effects, the second-order effects, and the interactions.

Upon varying the 5 factors, 5 coefficients each were obtained for the main and second-order effects, 10 coefficients were obtained for the interactions, and one constant was obtained for each response. The significances of the coefficients were examined by $t$-test. Analysis of variance was carried out to assess this model. Analysis of variance partitioned the total variances of a selected response into one part attributable to our regression model and another part attributable to the residuals. Analysis of variance also decomposed the residual vari- ation into the lack of fit and pure errors linked to the replicate error at the central point. The $F$-value was calculated from the mean squares to estimate significance. $R^{2}$ and $Q^{2}$ were used as parameters. $R^{2}$ is the goodness of fit of a parameter to the model and can be considered the upper bound of the predictability of the model. The equation for evaluating it is given below. $Q^{2}$ is the goodness of prediction parameter; it is based on the prediction residual sum of squares (PRESS), which is calculated from the cross-validation. Crossvalidation means that the data set was divided into training sets and test sets. A regression equation was then created from each training set, and the respective test set was used as the independent variable to predict the criterion variable. This procedure was used for all the data sets, and the PRESS was evaluated from the differences between the predicted values and the actual values to find $Q^{2}$, given in the equation below:

$$
R^{2}=\frac{S S-S S_{r e s i d}}{S S}=1-\frac{S S_{r e s i d}}{S S}=\frac{S S_{r e g}}{S S}, \text { and }
$$


Table 4. Regression coefficients and their $P$-values for the complete models for prediction of the 3 responses ${ }^{1}$

\begin{tabular}{|c|c|c|c|c|c|c|}
\hline \multirow[b]{2}{*}{ Item } & \multicolumn{2}{|c|}{$\operatorname{FAT}^{2}\left(Y_{1}\right)$} & \multicolumn{2}{|c|}{$\operatorname{AIR}\left(\log Y_{2}\right)$} & \multicolumn{2}{|c|}{$\operatorname{ICE}^{3}\left(Y_{3}\right)$} \\
\hline & $b$-Coefficient & $P$-value & $b$-Coefficient & $P$-value & $b$-Coefficient & $P$-value \\
\hline Constant & 57.105 & $0.000 * * *$ & 1.5677 & $0.000 * * *$ & 46.087 & $0.000 * * *$ \\
\hline Tem & -32.936 & $0.000 * * *$ & 0.1447 & $0.000 * * *$ & 13.305 & $0.000 * * *$ \\
\hline Mix & 0.528 & 0.756 & 0.0578 & $0.020 *$ & -4.561 & $0.013^{*}$ \\
\hline Cyl & -5.278 & $0.013^{*}$ & 0.0067 & 0.767 & 1.797 & 0.283 \\
\hline Das & 7.400 & $0.002 * *$ & -0.0286 & 0.245 & -2.559 & 0.159 \\
\hline Ovr & 8.951 & $0.001^{* *}$ & 0.0423 & 0.099 & -3.610 & 0.055 \\
\hline Tem $\times$ Tem & -7.335 & 0.062 & 0.0463 & 0.325 & 7.653 & 0.016 \\
\hline $\operatorname{Mix} \times \operatorname{Mix}$ & -0.835 & 0.814 & -0.0252 & 0.587 & 2.818 & 0.307 \\
\hline $\mathrm{Cyl} \times \mathrm{Cyl}$ & -3.205 & 0.376 & -0.0287 & 0.536 & 2.353 & 0.389 \\
\hline Das $\times$ Das & -7.928 & 0.053 & 0.0964 & 0.060 & 0.504 & 0.852 \\
\hline $\mathrm{Ovr} \times \mathrm{Ovr}$ & 6.973 & 0.136 & -0.0759 & 0.128 & -5.178 & 0.083 \\
\hline Tem $\times$ Mix & 1.565 & 0.397 & 0.0317 & 0.200 & 2.776 & 0.127 \\
\hline Tem $\times$ Cyl & -1.268 & 0.465 & -0.0007 & 0.975 & 1.391 & 0.387 \\
\hline Tem $\times$ Das & -0.163 & 0.274 & -0.0044 & 0.029 & -7.283 & $0.001 * *$ \\
\hline $\mathrm{Tem} \times \mathrm{Ovr}$ & -2.378 & 0.209 & -0.0002 & 0.992 & 0.182 & 0.918 \\
\hline $\mathrm{Mix} \times \mathrm{Cyl}$ & 2.655 & 0.138 & 0.0327 & 0.162 & 0.099 & 0.952 \\
\hline Mix $\times$ Das & -4.626 & $0.022^{*}$ & -0.0491 & $0.048 *$ & 2.310 & 0.172 \\
\hline Mix $\times$ Ovr & 1.592 & 0.418 & 0.0609 & $0.030 *$ & 0.360 & 0.836 \\
\hline Cyl $\times$ Das & 1.228 & 0.515 & 0.0155 & 0.530 & 1.315 & 0.450 \\
\hline $\mathrm{Cyl} \times \mathrm{Ovr}$ & 0.096 & 0.962 & -0.0226 & 0.397 & -1.778 & 0.343 \\
\hline $\mathrm{Das} \times \mathrm{Ovr}$ & 1.874 & 0.369 & 0.0072 & 0.787 & -0.934 & 0.628 \\
\hline$R^{2}$ & 0.989 & & 0.964 & & 0.919 & \\
\hline$R^{2}$ adjusted & 0.963 & & 0.882 & & 0.739 & \\
\hline$Q^{2}$ & 0.872 & & -26.53 & & -109.28 & \\
\hline
\end{tabular}

${ }^{1} \mathrm{Mix}=$ mix flow; Tem = drawing temperature; Ovr = overrun; Cyl = cylinder pressure; Das = dasher speed; FAT = rate of fat destabilization; AIR = mean air cell diameter; ICE = mean ice crystal diameter.

${ }^{2}$ Experimental data for number 25 are excluded.

${ }^{3}$ Experimental data for number 6 are excluded.

$* P<0.05 ; * * P<0.01 ; * * * P<0.001$.

$$
Q^{2}=\frac{S S-P R E S S}{S S}
$$

where $S S$ is the sum of squares of response values, $S S_{\text {resid }}$ is the sum of squares of residuals, and PRESS is the prediction residual sum of squares by cross-validation. The software MODDE6 (Umetrics AB, 2001) was used to plan the experiment and carry out the statistical analysis.

\section{RESULTS AND DISCUSSION}

\section{Sampling Conditions}

Table 3 shows the actual conditions under which the ice cream samples were taken and the responses obtained in the analysis. Nearly all the samples were taken under the conditions specified in the plan (central composite face-centered design); however, it was not possible to take them under the planned conditions for samples 4, 6, 7, and 11. For reasons having to do with the equipment, the overrun in sample 4 was not increased to the planned value of $120 \%$, and the combination of drawing temperature and overrun in sample 11 and the combinations of overrun and dasher speed in samples 6 and 7 were not possible. The continuous freezer specifications did allow an increase in the airflow to obtain the planned overrun, and air was supplied to the cylinder, but because the speed of the dasher specified in the conditions was too low, the air was not distributed uniformly in the ice cream. As a result, the samples removed after deaeration did not have the specified overrun. Even though the dasher speed was high, it was not possible to take samples under the planned condition for sample 11 because of the limit of the freezing ability; under a high mix flow rate $(100 \mathrm{~L} /$ h), high overrun (120\%), and high dasher speed (333 rpm), the drawing temperature could not be cooled down to $-6.5^{\circ} \mathrm{C}$. The sampling conditions were therefore changed to be as close to the originally specified conditions as possible, as shown for samples $4,6,7$, and 11 in Table 3.

\section{Complete Model}

The main, second-order, and interaction terms were used to fit a quadratic polynomial regression model to the response values provided in Table 3 . The mean AIR values were logarithmically transformed to obtain a pattern closer to a standard distribution. When the normal probability of the response residual values was 
Table 5. Regression coefficients and their $P$-values for the pruned model for prediction of the 3 responses ${ }^{1}$

\begin{tabular}{|c|c|c|c|c|c|c|}
\hline \multirow[b]{2}{*}{ Item } & \multicolumn{2}{|c|}{$\operatorname{FAT}^{2}\left(Y_{1}\right)$} & \multicolumn{2}{|c|}{$\operatorname{AIR}\left(\log Y_{2}\right)$} & \multicolumn{2}{|c|}{$\operatorname{ICE}^{3}\left(Y_{3}\right)$} \\
\hline & $b$-Coefficient & $P$-value & $b$-Coefficient & $P$-value & $b$-Coefficient & $P$-value \\
\hline Constant & 56.531 & $0.000 * * *$ & 1.576 & $0.000 * * *$ & 46.640 & $0.000 * * *$ \\
\hline Tem & -31.685 & $0.000 * * *$ & 0.171 & $0.000 * * *$ & 13.050 & $0.000 * * *$ \\
\hline Mix & -0.673 & 0.534 & 0.030 & 0.144 & -4.308 & $0.001 * * *$ \\
\hline Cyl & -4.182 & $0.001 * * *$ & 0.037 & 0.070 & & \\
\hline Das & 6.258 & $0.000 * * *$ & -0.054 & $0.016^{*}$ & -2.515 & $0.037 *$ \\
\hline Ovr & 10.110 & $0.000 * * *$ & 0.065 & $0.008^{* *}$ & -3.632 & $0.006^{* *}$ \\
\hline $\begin{array}{l}\text { Tem } \times \text { Tem } \\
\text { Mix } \times \text { Mix }\end{array}$ & -7.526 & $0.006^{* *}$ & & & 10.310 & $0.000 * * *$ \\
\hline $\begin{array}{l}\text { Cyl } \times \text { Cyl } \\
\text { Das } \times \text { Das }\end{array}$ & -8.164 & $0.007 * *$ & 0.110 & $0.016^{*}$ & & \\
\hline $\mathrm{Ovr} \times \mathrm{Ovr}$ & 5.098 & 0.101 & -0.084 & 0.076 & -3.092 & 0.205 \\
\hline $\begin{array}{l}\text { Tem } \times \text { Mix } \\
\text { Tem } \times \text { Cyl }\end{array}$ & & & & & 2.753 & $0.029^{*}$ \\
\hline $\begin{array}{l}\text { Tem } \times \text { Das } \\
\text { Tem } \times \text { Ovr }\end{array}$ & & & & & -7.067 & $0.000^{* * *}$ \\
\hline $\mathrm{Mix} \times \mathrm{Cyl}$ & 1.468 & 0.209 & 0.004 & 0.834 & & \\
\hline Mix $\times$ Das & -3.511 & $0.007 * *$ & -0.024 & 0.272 & 2.096 & 0.093 \\
\hline $\mathrm{Mix} \times \mathrm{Ovr}$ & & & 0.034 & 0.151 & & \\
\hline Cyl $\times$ Das & & & & & & \\
\hline $\mathrm{Cyl} \times \mathrm{Ovr}$ & & & & & & \\
\hline Das $\times$ Ovr & & & & & & \\
\hline$R^{2}$ & 0.983 & & 0.848 & & 0.919 & \\
\hline$R^{2}$ adjusted & 0.975 & & 0.773 & & 0.883 & \\
\hline$Q^{2}$ & 0.965 & & 0.562 & & 0.790 & \\
\hline
\end{tabular}

${ }^{1} \mathrm{Mix}=$ mix flow; Tem = drawing temperature; Ovr = overrun; Cyl = cylinder pressure; Das = dasher speed; FAT = rate of fat destabilization; AIR = mean air cell diameter; ICE = mean ice crystal diameter.

${ }^{2}$ Experimental data from number 25 are excluded.

${ }^{3}$ Experimental data from number 6 are excluded.

$* P<0.05 ; * * P<0.01 ; * * * P<0.001$.

Table 6. Analysis of variance of the 3 pruned models ${ }^{1}$

\begin{tabular}{|c|c|c|c|c|c|}
\hline \multirow[b]{2}{*}{ Item } & \multicolumn{5}{|c|}{ FAT pruned model } \\
\hline & $\mathrm{df}$ & SS & MS & $F$ & $P$ \\
\hline Total corrected & 29 & 22424.600 & 773.261 & & \\
\hline Regression & 10 & 22052.000 & 2205.200 & 112.442 & 0.000 \\
\hline Residual & 19 & 372.627 & 19.612 & & \\
\hline Lack of fit & 15 & 145.400 & 9.693 & 0.171 & 0.995 \\
\hline \multirow[t]{3}{*}{ Pure error } & 4 & 227.227 & 56.807 & & \\
\hline & \multicolumn{5}{|c|}{ AIR pruned model } \\
\hline & $\mathrm{df}$ & SS & MS & $F$ & $P$ \\
\hline Total corrected & 30 & 0.882 & 0.029 & & \\
\hline Regression & 10 & 0.748 & 0.075 & 11.197 & 0.000 \\
\hline Residual & 20 & 0.134 & 0.007 & & \\
\hline Lack of fit & 16 & 0.114 & 0.007 & 1.425 & 0.398 \\
\hline \multirow[t]{3}{*}{ Pure error } & 4 & 0.020 & 0.005 & & \\
\hline & \multicolumn{5}{|c|}{ ICE pruned model } \\
\hline & $\mathrm{df}$ & SS & MS & $F$ & $P$ \\
\hline Total corrected & 29 & 4773.870 & 164.616 & & \\
\hline Regression & 9 & 4389.060 & 487.673 & 25.346 & 0.000 \\
\hline Residual & 20 & 384.809 & 19.240 & & \\
\hline Lack of fit & 16 & 320.907 & 20.057 & 1.255 & 0.455 \\
\hline Pure error & 4 & 63.902 & 15.976 & & \\
\hline
\end{tabular}

${ }^{1} \mathrm{FAT}=$ rate of fat destabilization; AIR = mean air cell diameter; ICE = mean ice crystal diameter. 
A

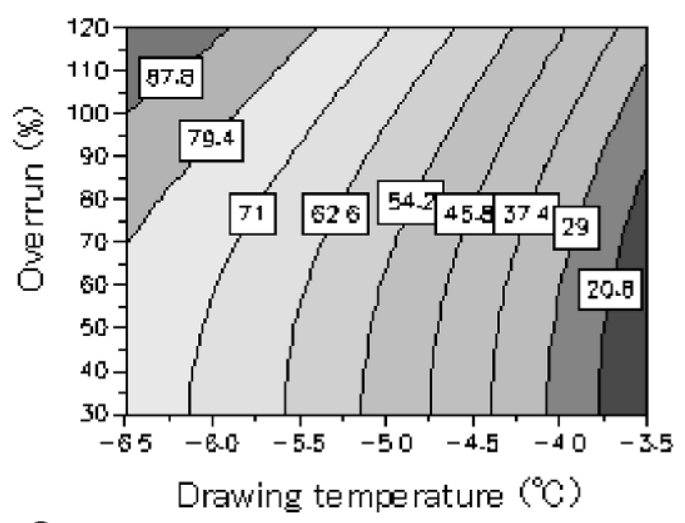

C



B

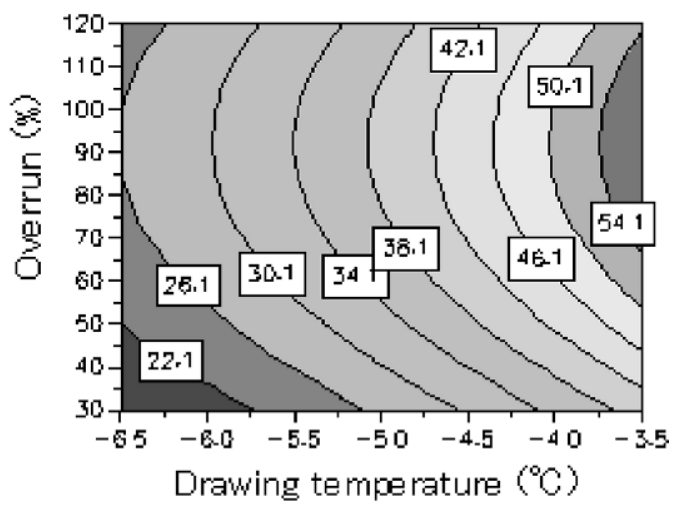

Figure 1. Contour plots of the 3 responses for drawing temperature and overrun. The other process parameters were set at their center values: mix flow rate $75(\mathrm{~L} / \mathrm{h})$; cylinder pressure $300(\mathrm{kPa})$; and dasher speed $222(\mathrm{rpm})$. A) Rate of fat destabilization (\%); B) mean air cell diameter $(\mu \mathrm{m})$; C) mean ice crystal diameter $(\mu \mathrm{m})$.

examined, outliers were found in the fraction of FAT in sample 25 and the mean ICE in sample 6 , so these were eliminated from further analysis.

Analysis of variance was carried out for the quadratic model based on the complete model (Table 4). High values, exceeding 0.9 , were found for $R^{2}$ for all 3 responses. Thus, the variances that were able to be modeled had high significance. In the variances that were unable to be modeled, it was also shown that the variance of the model error was not significantly larger than the variance of the pure experimental error (level of significance 0.05). The $P$-values from the $F$-test of the quadratic model are shown, along with the conditions.

Nevertheless, even though $R^{2}$ was this high, 2 of the responses, AIR and ICE, showed negative values for $Q^{2}$, the index of the model's ability to predict the results for new samples. A negative $Q^{2}$ value indicates an invalid model that does not have any predictive ability. It might therefore be suspected that irrelevant terms that are not influential to the responses are contained in the model.
Therefore, pruned models were constructed with the objective of obtaining simplified models with fewer terms regarding FAT while maintaining the same degree of precision and improving the values of $Q^{2}$ for AIR and ICE.

\section{Pruned Models}

With the goal of improving the predictive ability, pruned models were constructed (Table 5) by eliminating terms that did not contribute to accurate predictions of the 3 responses and by refitting the model. The regression coefficient for each term was examined with the $t$-test, and a value of $P \geq 0.2$ for the term was the criterion for dropping it. The $R^{2}$ and $Q^{2}$ values were monitored during the elimination process from the second-order to the interaction terms. Because of the hierarchy of terms in the model, when second-order and interaction terms were left in the model, the main terms included were also preserved. Tables 5 and 6 show the regression coefficients and results of the variance anal- 
A


B



Figure 2. Contour plots of the 3 responses for dasher speed and overrun. The other process parameters were set at their center values: mix flow rate $75(\mathrm{~L} / \mathrm{h})$; drawing temperature $-5.0^{\circ} \mathrm{C}$; and cylinder pressure $300(\mathrm{kPa})$. A) Rate of fat destabilization $(\%)$; B) mean air cell diameter $(\mu \mathrm{m}) ; \mathrm{C})$ mean ice crystal diameter $(\mu \mathrm{m})$.

ysis. The ANOVA tables showed that the variances of the model we designed were highly significant, and in the variances that we could not model, the variances of the model error were shown not to be significantly incompatible with the variances of the pure experimental error. Essential information was drawn from the sign (positive or negative) and the magnitude of the scaled and centered regression coefficients in the respective pruned models for the 3 responses.

\section{Pruned Model for FAT}

Ten of the terms in the complete model $\left(\mathrm{Mix}^{2}, \mathrm{Cyl}^{2}\right.$, Tem $\times$ Mix, Tem $\times$ Cyl, Tem $\times$ Das, Tem $\times$ Ovr, Mix $\times$ Ovr, Cyl $\times$ Das, Cyl $\times$ Ovr, Das $\times$ Ovr) were removed and refitted to obtain the pruned model for FAT, leaving a model consisting of 10 terms, aside from the constants.

High values of 0.983 and 0.965 were found for $R^{2}$ and $Q^{2}$, respectively, in this model, indicating that it provides a very good fit and dependable prediction of future observations. The regression coefficients also indicated that the drawing temperature was the domi- nant parameter, with approximately triple the effect of the second most important parameter, overrun (i.e., the coefficient for overrun had the second highest value after that for drawing temperature). Dasher speed had the third most influence over the ice cream characteristics and showed a remaining nonzero, second-order coefficient in addition to its main coefficient. In contrast, the coefficient of the mix flow rate had an extremely low effect; the value of this coefficient was approximately $1 /$ 50 that of the coefficient for drawing temperature. We concluded that this parameter had little direct effect on FAT. Kokubo et al. (1996) showed that fat destabilization rose when the drawing temperature was lowered, and that the higher the dasher speed (with some dependence on dasher shape) or the higher the overrun, the greater the fat destabilization. The model constructed in this study obtained similar results.

\section{Pruned Model for AIR}

Ten of the terms in the complete model $\left(\mathrm{Tem}^{2}, \mathrm{Mix}^{2}\right.$, $\mathrm{Cyl}^{2}$, Tem $\times$ Mix, Tem $\times$ Cyl, Tem $\times$ Das, Tem $\times$ Ovr, 
Cyl $\times$ Das, Cyl $\times$ Ovr, Das $\times$ Ovr) were removed and refitted to obtain the pruned model for AIR, leaving a model consisting of 10 terms and the constant. Values of 0.964 and -26.53 were found for $R^{2}$ and $Q^{2}$, respectively, for AIR in the complete model, in comparison with the values of 0.848 and 0.562 , respectively, in the pruned model. Although $R^{2}$ fell somewhat, $Q^{2}$ was dramatically improved. Generally, it can be assumed that $R^{2}$ will not significantly decrease when terms are eliminated, but in this case, the initial $R^{2}$ was extremely high, whereas $Q^{2}$ was negative. Such an equation is not of much value for predicting the effects of parameters, so $Q^{2}$ was given a higher priority here, and the reduction of $R^{2}$ to a value that remained significant was deemed to be an inevitable and acceptable tradeoff. Of all the deleted terms, the elimination of Tem $\times$ Das produced the greatest improvement in $Q^{2}$. The 0.848 value for $R^{2}$ in this pruned model could not be called excellent, but it was high enough to be considered valuable for fitting.

Because the coefficients for the regression equation were transformed logarithmically, as mentioned earlier, their absolute values diminished, but as seen for the pruned model for FAT, the most important variable was the drawing temperature, followed by the overrun; the coefficient for the drawing temperature was approximately 2.6 times that for the overrun. The difference between this pruned model and that for FAT was that the mix flow rate and cylinder pressure showed roughly equal effects on AIR.

As stated, the regression coefficient for each term was examined with the $t$-test, and terms with $P \geq 0.2$ were dropped. According to this criterion, second-order terms were preserved for the dasher speed and overrun.

\section{Pruned Model for ICE}

Eleven of the terms in the complete model (Cyl, $\mathrm{Mix}^{2}$, $\mathrm{Cyl}^{2}, \mathrm{Das}^{2}$, Tem $\times$ Cyl, Tem $\times$ Ovr, Mix $\times$ Cyl, Mix $\times$ Ovr, Cyl $\times$ Das, Cyl $\times$ Ovr, Das $\times$ Ovr) were removed and refitted to obtain the pruned model for ICE, leaving a model consisting of 9 terms plus constants.

A value of 0.919 was found for $R^{2}$ in this model. There was no change from the value in the complete model, whereas $Q^{2}$ was dramatically improved from a value of -109.28 to +0.790 .

As the results for the other 2 pruned models show, drawing temperature had the highest effect on ice cream characteristics. In contrast, the mix flow rate was the second most influential factor for ICE; its coefficient was approximately one-third the value of the coefficient for drawing temperature. The mix flow rate was followed by overrun and dasher speed. Also of note is that no cylinder pressure terms were preserved in this model.

\section{Influence of the Drawing Temperature and Overrun on Each Response}

Figure 1 presents contour plots of the response surfaces for each pruned model to incorporate only the drawing temperature and the next or third largest parameter of overrun. All the other parameters were fixed at their central points.

The drawing temperature was dominant for FAT, as can be seen in Figure 1A, but a growing influence from overrun could be seen at higher values of overrun. The FAT was minimized at high drawing temperatures, between -3.75 and $-3.5^{\circ} \mathrm{C}$, and low overrun values, whereas it reached a maximum at low drawing temperatures, between -6.0 and $-6.5^{\circ} \mathrm{C}$, and high overruns, between 100 and $120 \%$.

Figure 1B shows that an overrun of $80 \%$ was borderline for AIR; at higher overrun levels, drawing temperature had the dominant influence over AIR, whereas at lower overrun levels, overrun itself was dominant. At high drawing temperatures, between -3.75 and $-3.5^{\circ} \mathrm{C}$, and overruns of approximately $70 \%$, AIR was predicted to reach a maximum, whereas it was predicted to reach a minimum at drawing temperatures of approximately -5.75 to $-6.5^{\circ} \mathrm{C}$ and low overruns of 50 to $30 \%$.

Figure $1 \mathrm{C}$ shows the influence of overrun on abrupt ICE increases at drawing temperatures below $-5.0^{\circ} \mathrm{C}$ in a unique response surface. The diameter reached a maximum at approximately $-3.5^{\circ} \mathrm{C}$, whereas at a drawing temperature of $-6.0^{\circ} \mathrm{C}$ and overruns of $100 \%$ or more, ICE showed a minimum. In other words, when the drawing temperature was greater than $-5^{\circ} \mathrm{C}, \mathrm{ICE}$ was strongly dependent on the drawing temperature, but when the drawing temperature was less than $-5^{\circ} \mathrm{C}$, not only the temperature, but also the overrun influenced the ICE.

Flores and Goff (1999) reported the same result. They found that overruns of $50 \%$ or less had no direct influence on ICE. Under overruns of $70 \%$ or more, however, the uniform distribution of air cells reduced the incidence of collisions between ice crystals and tiny ice crystals were produced, which affected the microstructure of the ice cream.

No significant differences were seen in ICE when the drawing temperatures were between -5 and $-6.5^{\circ} \mathrm{C}$ and the overrun was below $70 \%$ in the model constructed in this study. At higher overruns, however, the ICE were observed to be smaller. 


\section{Influence of Dasher Speed and Overrun on Each Response}

It was clear from the regression coefficients in the pruned models that the drawing temperature was the factor with the greatest influence on all 3 responses. Figure 2 shows the influence of the second and third factors, dasher speed and overrun, on ice cream characteristics. As in the simplification above, all the other factors were set to their central values.

When overrun and dasher speed were high, FAT reached its maximum. It continued to increase as the overrun was raised (Figure 2A).

Mean air cell diameter (Figure 2B) reached a maximum at dasher speeds below $150 \mathrm{rpm}$ and overruns from $70 \%$ to approximately $100 \%$. We currently ascribe this to insufficient agitation of the added air at low dasher speeds. The most effective way to obtain fine air cells in the mix was to increase the dasher speed at low overruns. This model predicts no particular increase in AIR once both the dasher speed and overrun have been raised above certain levels.

The ICE analysis (Figure 2C) clearly showed that tiny ice crystals were formed when both the overrun and dasher speed were raised to their maximum. As mentioned earlier, increasing overruns led to the formation of smaller ice crystals. Additionally, an increasing dasher speed broke large air cells in the ice cream into smaller ones during freezing (Figure 2B), and the welldispersed smaller air cells consequently reduced the probability of collisions between ice crystals.

Schwartzberg (1990) speculated on ice crystal formation in an ice cream freezer, where dendrites grow from the wall of the freezer barrel and are then broken off and transferred to the bulk flow by the action of the rotating dasher blades. According to this model, increasing the dasher speed would decrease dendrite growth. As a result, the primary nuclei transferred to the bulk would be smaller. These observations support the formation of tiny ice crystals under conditions in which both the overrun and dasher speed are raised to their maximum, as mentioned in our work. Russell et al. (1999) reported that increasing the dasher speed causes an elevation in product temperature, through increased dissipation of frictional energy, which leads to dissolution of small crystals and enhanced crystal aggregation, giving larger crystal sizes in the exit stream. These data reported by Russell et al. (1999) are not in agreement with those in our investigation. This work showed that a faster dasher speed led to a smaller ice crystal size, and the effect of frictional energy attributable to the increasing dasher speed on ice crystal size was never observed.

\section{CONCLUSIONS}

We succeeded in constructing a model of ice cream production based on response surface methodology. This model used a systematic analysis to make accurate predictions of the effects of 5 conditions in a continuous freezer (mix flow rate, overrun, cylinder pressure, drawing temperature, dasher speed) on 3 typical constituent parameters of ice cream (FAT, AIR, ICE). Previous reports have already partially described how the various freezer parameters affect the ice cream mix, but this quantitative study showed the effects of key freezer conditions alone and in synergistic combinations. Once a model like this has been established, a user can obtain contour-line visualizations of the correlations between freezer parameters and ice cream characteristics. The simultaneous effects of drawing temperature and overrun on ice crystal size are a good example: a simple approach for obtaining fine crystals is to lower the drawing temperature; however, when ice cream is being frozen at temperatures below $-5.1^{\circ} \mathrm{C}$, it is also possible to obtain finer ice crystals by increasing the overrun. This is just one example of the techniques that can be revealed by examining the results of this simulation.

In the meantime, there have been many reports describing the sensations provided by different degrees of fat destabilization, air cell sizes, and ice crystal sizes. If this model of freezing conditions and ice cream mix can be developed to incorporate the relationship between the freezer factors and the sensory parameters of ice cream, it will become extremely useful for the quality control of ice cream. This kind of model will allow manufacturers of ice cream to respond quickly to consumer needs uncovered by marketing research and to create ice cream with new qualities. It will be a very significant resource in this industry.

\section{REFERENCES}

Bolliger, S., B. Kornbrust, H. D. Goff, B. W. Tharp, and E. J. Windhab. 2000. Influence of emulsifiers on ice cream produced by conventional freezing and low-temperature extrusion processing. Int. Dairy J. 10:497-504.

Christensen, F. H., and A. M. Andersen. 2003. Influence of different parameters on the quality of bottom-filled moulded ice cream sticks. Pages 326-349 in Proc. 2nd Int. Dairy Fed. Int. Symp. Ice Cream, Thessaloniki, Greece. H. D. Goff and B. W. Tharp, ed. IDF, Brussels, Belgium.

Donhowe, D. P., R. W. Hartel, and R. L. Bradley Jr. 1991. Determination of ice crystal size distributions in frozen deserts. J. Dairy Sci. 74:3334-3344.

Flores, A. A., and H. D. Goff. 1999. Ice crystal size distributions in dynamically frozen model solutions and ice cream as affected by stabilizers. J. Dairy Sci. 82:1399-1407.

Goff, H. D. 1997. Colloidal aspects of ice cream-A review. Int. Dairy J. 7:363-373.

Goff, H. D., and W. K. Jordan. 1989. Action of emulsifiers in promoting fat destabilization during the manufacture of ice cream. J. Dairy Sci. 72:18-29. 
Koc, A. B., P. H. Heinemann, and G. R. Ziegler. 2003. A process for increasing the free fat content of spray-dried whole milk powder. J. Food Sci. 68:210-216.

Kokubo, S., K. Sakurai, K. Hakamata, M. Tomita, and S. Yoshida. 1996. The effect of manufacturing conditions on the de-emulsification of fat globules in ice cream. Milchwissenschaft 51:262-265.

Russell, A. B., P. E. Cheney, and S. D. Wantling. 1999. Influence of freezing conditions on ice crystallization in ice cream. J. Food Eng. 39:179-191.

Schwartzberg, H. G. 1990. Food freeze concentration. Pages 127-202 in Biotechnology and Food Process Engineering. H. G. Schwartzberg, and M. A. Rao, ed. Marcel Dekker, New York, NY.
Tong, P. S., W. K. Jordan, and G. Houghton. 1984. Response surface methodology to study fat destabilization and development of overrun in ice creams produced with polyunsaturated safflower oil and milk fat blends. J. Dairy Sci. 67:779-793.

Umetrics AB. 2001. MODDE6. Umetrics AB, Umeå, Sweden.

Ünal, B., S. Metin, and N. D. Işıklı. 2003. Use of response surface methodology to describe the combined effect of storage time, locust bean gum and dry matter of milk on the physical properties of low-fat set yoghurt. Int. Dairy J. 13:909-916.

van der Ven, C., H. Gruppen, D. B. A. de Bont, and A. G. J. Voragen. 2002. Optimization of the angiotensin converting enzyme inhibition by whey protein hydrolysates using response surface methodology. Int. Dairy J. 12:813-820. 